\title{
OCORRÊNCIA DE Bacillus sporothermodurans EM LEITE UAT INTEGRAL E DESNATADO
}

\author{
Cassiano BUSATTA, Eunice VALDRUGA², Rogério Luis CANSIAN
}

\section{RESUMO}

Por sua composição completa e balanceada, o leite é um substrato ideal para o desenvolvimento de diversos grupos de microrganismos. Bactérias, fungos, vírus e outros podem provocar significativas alterações no leite e derivados. Apesar do tratamento a Ultra Alta Temperatura a que o leite longa vida é submetido, constatou-se nos últimos anos, a presença de um novo tipo de bactéria altamente resistente ao calor, denominada Bacillus sporothermodurans, em função de sua capacidade de formação de esporos. O presente trabalho teve como objetivos verificar a presença desta bactéria em leites UAT (Ultra Alta Temperatura) integral e desnatado, comercializados na região do Alto Uruguai - RS e quantificar a capacidade de resistência à altas temperaturas das formas encontradas. Os resultados revelaram a presença desta bactéria em $54,5 \%$ das marcas analisadas, com $36,5 \%$ dos lotes analisados contaminados. A resistência térmica desta bactéria em relação ao teor de lipídios mostraram tendência a uma maior resistência em leite integral. Pode-se concluir que, embora esta bactéria seja descrita como não patogênica, é importante salientar a importância de novos estudos para obter maiores conhecimentos sobre suas características, uma vez que sua presença mostrou-se comum.

Palavras-chave: Bacillus sporothermodurans; UHT; UAT; endoesporos.

\section{SUMMARY}

OCCURRENCE OF Bacillus sporothermodurans IN INTEGRAL AND SKIMMED UHT MILK. Due to its full and balanced composition, milk comprises an ideal raw material for the development of a variety of groups of microorganisms. Bacteria, fungus, viruses and others can provoke significant alterations in milk and derivatives. Despite the UHT process, in which long-life milk is submitted, the presence of a new type, highly thermal-resistant bacterium, called Bacillus sporothermodurans, was verified in the last years, due possibly to its capacity of spores formation. This work is aimed at investigating the presence of this bacterium in both integral and skimmed UHT milk, commercialized in the north and neighbor region of Rio Grande do Sul state and to quantify the resistance capacity to high temperatures processing. Results revealed the presence of this bacterium in $54.5 \%$ of the products analyzed with $36.5 \%$ of the analyzed batches contaminated. The thermal resistance of this bacterium with regard to lipids content was demonstrated to be greater in integral milk. We can conclude that even though this bacterium is described as not being pathogenic, it might be relevant to conduct new investigations towards assessing its characteristics, once its presence has been noticed to be very common.

Keywords: Bacillus sporothermodurans; UHT; endoesporos.

\section{1 - INTRODUÇÃO}

A análise microbiológica atua como ferramenta fundamental para a obtenção de dados sobre a qualidade, sanidade, higiene e segurança na produção de alimentos; desta forma, tem sido adotada na indústria de alimentos para o controle de qualidade [3].

A flora bacteriana do leite varia consideravelmente, em número e espécie, dependendo de como o mesmo se contamina. O leite proveniente de animais sadios, ordenhados de forma asséptica, contém poucos microrganismos, porém pode sofrer contaminação a partir do ambiente e do homem, dependendo dos métodos utilizados no manejo dos animais, os quais determinarão a carga

Recebido para publicação em 17/07/2002. Aceito para publicação em 31/08/2005 (000882).

Universidade Regional Integrada do Alto Uruguai e das MissõesURI-Campus Erechim. Endereço: Av. 7 de setembro, n.1621. CEP: 99700-000,Erechim-RS, Brasil.E-mail:cansian@uricer.edu.br A quem a correspondência deve ser enviada. microbiana e as espécies envolvidas [6, 7].

Conforme FRANCO \& LANDGRAF [3], a esterilização, por sua vez, significa a destruição de todas as células viáveis que possam ser enumeradas por técnica apropriada de semeadura. Em alimentos, emprega-se o termo "esterilização comercial" para indicar que nenhum microrganismo viável pode ser detectado pelos métodos usuais de semeadura, ou ainda que, o número de sobreviventes é tão baixo que nessas condições de envasamento e armazenamento é insignificante.

Leite UAT (ultra alta temperatura) é o leite homogeneizado submetido a temperatura de 130 a $150^{\circ} \mathrm{C}$ por 2 a 4 segundos, mediante processo térmico de fluxo contínuo, imediatamente resfriado a temperatura inferior a $32^{\circ} \mathrm{C}$ e envasado sob condições assépticas em embalagens estéreis e hermeticamente fechadas [2].

De acordo com FRANCO \& LANDGRAF [3], as bactérias pertencentes ao gênero Bacillus compreendem um grande número de espécies, estando relatadas até o momento, 48 espécies diferentes. As bactérias deste gênero caracterizam-se por uma intensa atividade metabólica, já que produzem enzimas que degradam muitos substratos orgânicos. Devido a esta característica, a identificação desses microrganismos é bastante complicada, não havendo um consenso geral sobre a melhor forma de fazê-la. 
Segundo PETTERSSON et al. [4], o Bacillus sporothermodurans apresenta-se sob a forma de bastonetes longos $(>30 \mu \mathrm{m})$ e filamentosos com aproximadamente $0,7 \mathrm{~mm}$ de diâmetro, os quais produzem coloração desigual quando submetidas à reação de Gram e aparência granular ou de uma fileira de pérolas. As células também apresentam motilidade por meio de flagelos peritricos e são aeróbias estritas. Os esporos possuem forma elipsoidal, estando localizados em posição terminal sem distender o esporângio, embora sejam raramente observados em culturas de laboratório normais. As colônias são pequenas, lisas e de coloração de quase branca a bege e não há pigmento solúvel.

O Bacillus sporothermodurans parece resistir às condições de tempo e temperatura empregadas atualmente no sistema UAT de processamento térmico, pelo método de injeção indireta de vapor, fato que desperta preocupação pela possibilidade de prejuízos com a condenação de lotes do produto, acrescida do fato do consumo de leite em embalagens "longa vida" estar aumentando significativamente no Brasil [1].

Em se tratando de um problema relativamente recente, há escassez de dados técnicos a respeito desta bactéria na literatura internacional, principalmente com relação a seu comportamento, suas características fisiológicas e bioquímicas, mecanismos do processo de deterioração dos produtos, sua resistência térmica, características ecológicas, niveis de contaminação e técnicas de isolamento.

Com o objetivo de detectar a presença do Bacillus sporothermodurans e verificar a influência do teor de lipídios na sua capacidade de resistência à altas temperaturas, foram realizadas análises de todas as marcas comercializadas na região Norte do Rio Grande do Sul.

\section{2 - MATERIAL E MÉTODOS}

Foram utilizadas amostras de 11 marcas de leite UAT comercializadas na região Alto Uruguain - RS, sendo adquiridas oito unidades de cada marca, totalizando 88 unidades analisadas.

De cada marca analisada, foram adquiridas amostras de leite integral e desnatado em dois lotes distintos, com a finalidade de estabelecer relações com a presença da bactéria em relação ao teor de lipídios. Em cada unidade analisada foi realizado plaqueamento em duplicata totalizando 176 placas.

De cada amostra foram catalogadas informações do rótulo das embalagens, sendo o nome codificado por letras.

As amostras foram incubadas em embalagem original por sete dias a uma temperatura em torno de $37^{\circ} \mathrm{C}$, com objetivo de enriquecer o leite contaminado. Após a incubação, amostras de leite foram inoculadas em meio de cultura BHI Agar e Agar Nutriente enriquecido com vitamina $\mathrm{B}_{12}$, a uma temperatura em torno de $37^{\circ} \mathrm{C}$ com objetivo de obter o crescimento e isolar a bactéria $[1,5]$. Ao re- alizar o plaqueamento, foi verificado também o $\mathrm{pH}$, com o objetivo de comparar amostras contaminadas com amostras estéreis.

Foi feita a coloração de Gram de colônias isoladas para analisar a sua morfologia e comparar com a bibliografia.

Para avaliar a capacidade de resistência ao tratamento térmico em autoclave, foram separadas aliquotas de amostras contaminadas que variaram de $10^{4}$ a $10^{5}$ UFC (integral e desnatado) em enrlemeyers estéreis, e submetidas a variações de temperatura e tempo de 5,10 , 15 e 20 minutos a $121^{\circ} \mathrm{C}$ em auto-clave e posteriormente plaqueadas em duplicata e incubadas em estufa $\left(37^{\circ} \mathrm{C}\right)$ para comparar quantitativamente o seu desenvolvimento.

\section{3 - RESULTADOS E DISCUSSÃO}

As colônias cultivadas em laboratório durante as análises realizadas, apresentaram-se em forma de colônias típicas, ou seja, pequenas, lisas com coloração cinza-clara e bordas ligeiramente onduladas, conforme citado por PETTERSSON et al. [4]. A visualização dessas características podem ser observadas na Figura 1, a qual mostra um repique em aumento, realizado em meio de cultura Agar Nutriente enriquecido com vitamina $B_{i 2}$.

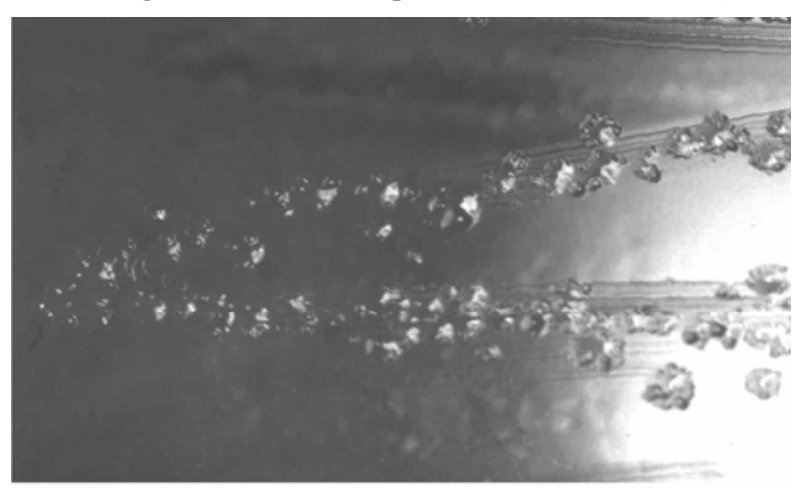

FIGURA 1 - Imagem de colônias típicas de Bacillus sporothermodurans. Aumento 9x

Os resultados das análises feitas para determinar a presença da bactéria, revelaram que 6 marcas $(54,5 \%)$ apresentavam-se contaminadas por B. sporothermodurans. De acordo com PETTERSSON et al. [4], o tratamento empregado no leite UAT, deveria resultar na destruição de quaisquer células vegetativas e endosporos presentes na matéria-prima crua, o que não se confirma no presente trabalho, onde os resultados revelam a contaminação positiva na maioria das marcas analisadas, como mostra a Figura 2, permitindo afirmar que o resultado é expressivo.

Os trabalhos realizados, até momento, revelam que a bactéria não é patogênica, mas o conceito dado poderá mudar com estudos posteriores, uma vez que se conhece muito pouco em relação ao seu metabolismo e a seu comportamento no trato digestivo humano. 


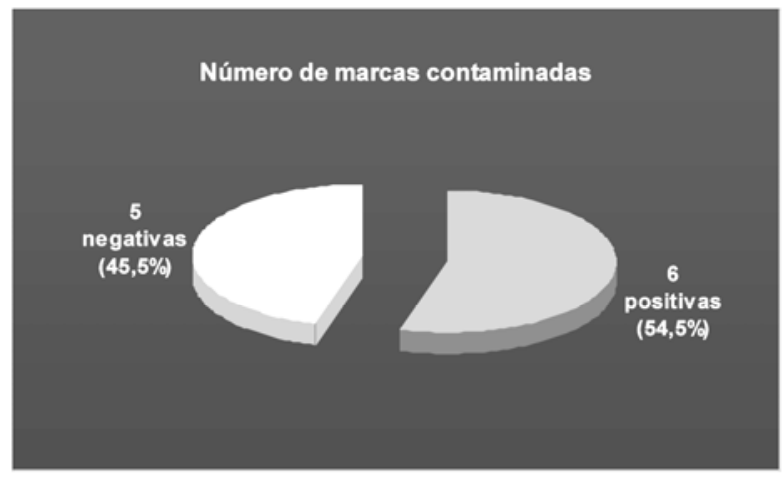

FIGURA 2 - Índice de marcas contaminadas

$\mathrm{O}$ pH das amostras ficou entre 6,40 e 6,90, sendo que a variação do $\mathrm{pH}$ não ultrapassou 0,15 unidades quando comparadas as amostras incubadas com amostras não incubadas, ficando de acordo com as regras propostas pela Associação Brasileira de Leite Longa Vida, que preconiza que esta não deve ultrapassar 0,2 unidades.

Microscopicamente, ao analisar a bactéria em laboratório usando a técnica de coloração de Gram, as células apresentaram-se sob a forma de bacilos longos e filamentosos, produzindo coloração desigual (Figura 3), concordando com PETTERSSON et al. [4].

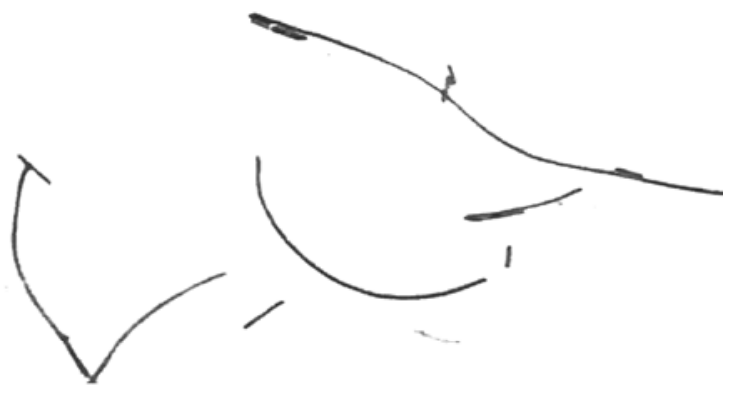

FIGURA 3 - Visualização microscópica do Bacillus sporothermodurans. Aumento 1000x

Em relação ao número total de lotes (44 lotes) analisados os resultados mostraram 16 lotes contaminados (Figura 4), representando um indice de 36,5\%.

Em relação aos resultados das análises de presença da bactéria realizadas de acordo com o teor de gorduras, verificou-se um índice maior de contaminação no número de lotes de leite desnatado do que em relação aos lotes de leite desnatado (Figura 5). Por serem bactérias aeróbias estritas, conforme PETTERSSON et al. [4], provavelmente o oxigênio difundido no leite desnatado seja maior, possibilitando um desenvolvimento com facilidade antes de iniciar a esporulação novamente.

Os resultados das análises de resistência ao tratamento térmico, revelaram maior resistência em autoclave os esporos presentes no leite integral (Figura 6).

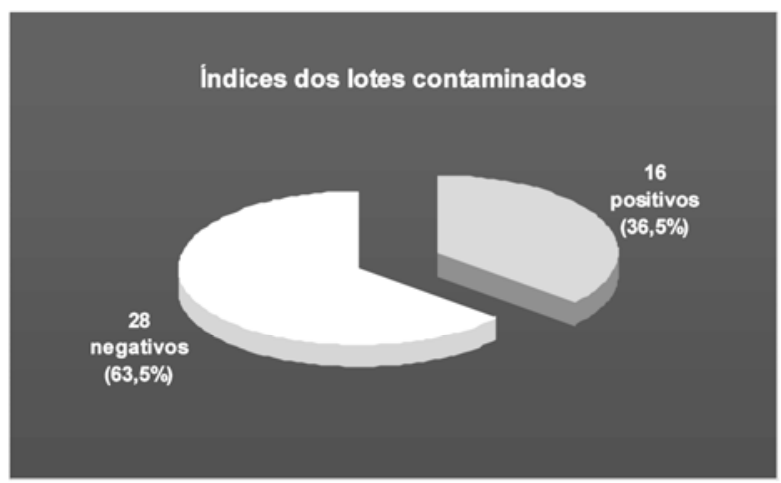

FIGURA 4 - Total de lotes contaminados

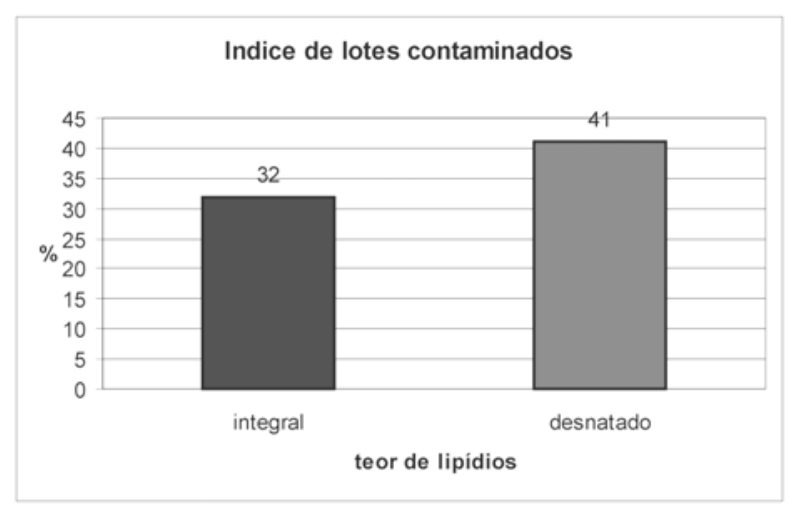

FIGURA 5 - Relação de lotes contaminados de acordo

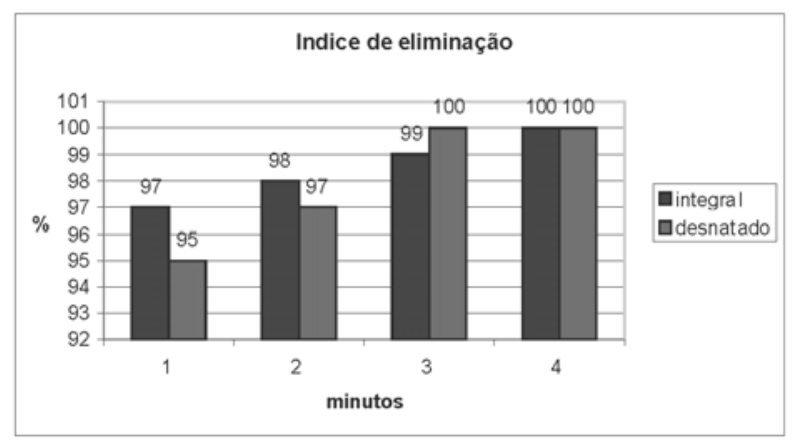

FIGURA 6 - Dados demostrando o índice de eliminação (\%) à temperatura de $121^{\circ} \mathrm{C}$ em relação ao tempo $(1=5 \mathrm{~min}$.; $2=10$ min.; 3 = $15 \min$; 4 = 20min.)

De acordo com FRANCO \& LANDGRAF [3], a presença de lipídios no alimento aumenta a capacidade de resistência térmica de alguns microrganismos. Essa proteção é, algumas vezes, denominada proteção lipídica. Presume-se que o aumento na resistência térmica esteja diretamente ligado ao fato de a gordura afetar o conteúdo de água na célula. Estudos com C. botulinum, demonstraram que ácidos graxos de cadeia longa são melhores protetores que os ácidos graxos de cadeia curta. A resistência dos esporos parece ser decorrente da desidratação 
do protoplasto, mineralização e adaptação térmica.

Para a destruição total dos esporos presentes no leite integral, os resultados revelam que há necessidade de um tempo acima de 15 minutos, a $121^{\circ} \mathrm{C}$, sendo que a eliminação nesse tempo foi de $99 \%$, restando alguns esporos que poderiam vir a germinar em condições favoráveis. Em relação ao leite desnatado, constatou-se que os esporos não resistiram ao tempo de 15 minutos, a $121^{\circ} \mathrm{C}$, ou seja, a eliminação de esporos capazes de germinarem foi total.

Com o tratamento térmico de 20 minutos, a $121^{\circ} \mathrm{C}$ houve eliminação total dos esporos em todas as amostras (integral e desnatado).

\section{4 - CONCLUSÕES}

Os resultados encontrados permitem concluir que foi encontrado em 54\% das marcas dos leites UHT analisados.

A relação do teor de gordura com a capacidade de resistência ao tratamento térmico da bactéria, nos mostra que possivelmente as moléculas de lipídios contribuem na resistência a altas temperaturas, determinado temperaturas distintas para a eliminação total dos esporos.

Convém ressaltar a importância de novos estudos sobre a referida bactéria, pois, por ser um assunto relativa- mente novo e presente em nosso meio, há poucos dados encontrados na literatura.

\section{5 - REFERÊNCIAS BIBLIOGRÁFICAS}

[1] ABLV (Associação Brasileira de Leite Longa Vida). Comunicação pessoal. 1997.

[2] BRASIL, Ministério da Agricultura, Abastecimento e Reforma Agrária. Portaria n. 146, de 07mar. 1996. Regulamentos técnicos de identidade e qualidade dos produtos lácteos. Diário Oficial da União, Brasília, 11 de mar. 1996. Seção 1. p.3978 3986.

[3] FRANCO, B. D. G. M.; LANDGRAF, M., 1996, Microbiologia de Alimentos. São Paulo: Editora Atheneu.

[4] PETTERSSON, B.; LEMBKE, F,; HAMMER, P.; STACKEBRANDT, E. e PRIEST, F. G., "Bacillus sporothermodurans, new species producing highly heatresistent endospores". International Journal of Systematic Bacteriology, v. 46, n.3, p.759-764, 1996.

[5] SILVA, N.; JUNQUEIRA, V.C.A.; SILVEIRA, N.F.A.., 1997, Manual de Métodos de Análise Microbiológica de Alimentos. São Paulo: Livraria Varela.

[6] TRONCO, V.M., 1997, Leite. Editora Universidade Federal de Santa Maria, Santa Maria.

[7] VARNAM, A. H.; SUTHERLAND, J. P., 1997, Leche y Productos Lacteos. Editora Ascriba, Zaragoza. 